\title{
The potential impact of primary headache disorders on stroke risk
}

\author{
Chia-Lin Tsai ${ }^{1,2}$, Chung-Hsing Chou ${ }^{1,2}$, Pei-Jung Lee ${ }^{3}$, Jiu-Haw Yin ${ }^{1,4}$, Shao-Yuan Chen ${ }^{5,6,7}$, Chun-Chieh Lin ${ }^{1}$, \\ Yueh-Feng Sung ${ }^{1}$, Fu-Chi Yang ${ }^{1}$, Chi-Hsiang Chung ${ }^{8,9,10}$, Wu-Chien Chien ${ }^{9,10}$, Chia-Kuang Tsai $^{1}$ and \\ Jiunn-Tay Lee Le, $^{1,2^{*}}$
}

\begin{abstract}
Background: Headache such as migraine is associated with stroke. Studies focused on primary headache disorders (PHDs) as a risk factor for stroke are limited. The purpose of this population-based cohort study was to explore whether patients with PHDs were at a high risk for developing stroke.

Methods: A total of 1346 patients with PHDs were enrolled and compared with 5384 age-, gender- and co-morbiditymatched control cohorts. International Classification of Diseases, Clinical Modification codes were administered for the definition of PHDs, stroke, and stroke risk factors. Cox proportional-hazards regressions were performed for investigating hazard ratios (HR)

Results: PHDs patients exhibited a 1.49 times (95\% Cl:1.15-1.98, $p<0.01$ ) higher risk for developing ischaemic stroke compared with that of control cohorts. Both migraine ( $\mathrm{HR}=1.22,95 \% \mathrm{Cl}: 1.13-1.97, p<0.05)$ and tension-type headache $(H R=2.29,95 \% \mathrm{Cl}: 1.22-2.80, p<0.01)$ were associated with an increased risk of ischemic stroke. Females with PHDs were at greater risk of developing ischaemic stroke $(H R=1.49,95 \% \mathrm{Cl}: 1.13-1.90, p<0.01)$ than those without PHDs. PHDs patient aged 45 to 64 years displayed significantly higher risk to develop ischaemic stroke ( $\mathrm{HR}=1.50,95 \% \mathrm{Cl}: 1.11-2.10, p$ $<0.05)$ than the matched controls. The impact of PHDs on ischaemic stroke risk became gradually apparent by different following time intervals beyond 2 years after first diagnosis.
\end{abstract}

Conclusion: PHDs is suggestive of an incremental risk for ischaemic stroke with gender-dependent, age-specific and time-dependent characteristics.

Keywords: Tension-type headache, Migraine, Non-migrainous headache, Ischaemic stroke, Risk factor

\section{Background}

Stroke is one of leading causative factors of permanent disability and mortality worldwide. It is considered as a preventive disorder and preventive interventions are of more considerable value compared with therapeutic approaches [1]. The crucial risk factors for stroke had been established, including non-modifiable (age, gender) and modifiable (hypertension, diabetes, dyslipidemia,

\footnotetext{
* Correspondence: jiunntay@gmail.com

The study was performed at Department of Neurology, Tri-Service General Hospital, National Defense Medical Center, Taipei, Taiwan, R.O.C.

'Department of Neurology, Tri-Service General Hospital, National Defense Medical Center, No.325, Sec. 2, Cheng-Kung Road, 11490 Taipei, Taiwan, Republic of China

${ }^{2}$ Graduate Institute of Medical Sciences, National Defense Medical Center, Taipei, Taiwan, ROC

Full list of author information is available at the end of the article
}

smoking, and atrial fibrillation) [2]. Up to $40 \%$ patients with stroke have been reported to have medical conditions in addition to the traditional risk factors, which contribute to pathogenesis of stroke in certain populations [3, 4]. It is suggested that investigation of certain medical diseases or conditions to establish a full-scale account of risk factors for stroke achieve an appropriate prevention with great value.

Primary headache disorders (PHDs) include migraine, tension-type headache, cluster headache, and other primary headaches [5]. PHDs is known as recurrent or persistent pain of head without any clear underlying mechanism, which significantly impair patients' life quality $[6,7]$. Migraine is reported as a risk factor of stroke [8], whereas non- migraine headaches have received less notice regardless of high prevalence $[9,10]$. Given the 
advantages of the Taiwan National Health Insurance program, the present study was intended to explore increased risks of stroke in patients with PHDs.

\section{Methods}

\section{Data sources}

The National Health Insurance (NHI) system, instituted in 1995, is a mandatory social insurance program that offers comprehensive health care coverage to all residents of Taiwan. This retrospective study was conducted using the data retrieved from Longitudinal Health Insurance Database (LHID 2005) released by Taiwan National Health Research Institute (NHRI) covering clinical data between 1997 and 2010. The LHID 2005 consisted of declared information, including records of inpatient, outpatient, and ambulatory care services of one million individuals insured, who randomly extracted from a database of more than 25 million cases. The International Classification of Diseases, Ninth Revision, Clinical Modification (ICD-9-CM) was employed for classification of diseases. According to Taiwan NHRI, there was no significant difference in the distribution of age and gender between the patients in the LHID 2005 and the original database [11]. The patient identity was blinded as a scrambled and anonymous number to protect the privacy of the insured people. Previous reports have shown the reliability of the diagnosis coding in the LHID [12, 13]. The study protocol was reviewed and approved by Institutional Review Board of Tri-Service General Hospital (TSGHIRB No.: 1-104-05-112).

\section{Study population}

From 967,854 individual outpatient care data in the LHID from 2000 to 2005, patients with new diagnosis of PHD were identified and included. The subjects with a previous diagnosis of PHDs and stroke or with lacking identification of sex or individuals under 18 years of age were excluded. Patients were diagnosed with migraine (ICD-9-CM 346), tension-type headache (ICD-9-CM 307.81), and other headache syndromes (ICD-9-CM 339) for the first time from 2000 to 2005 $(N=1,346)$, as the study cohort. We randomly selected 5,384 individuals with a ratio of 4:1, to match the PHDs group according to age, gender and comorbidities include hypertension, diabetes mellitus, ischaemic heart diseases, hyperlipidaemia and atrial fibrillation. The diagnosis date of PHDs was considered as the index date. Each case was then followed up from the index date up to the date of stroke developed. For cases who did not suffer a stroke, the endpoint of tracking was defined as the last day of the study period (December 31, 2010) or the termination date of insurance.

\section{Definition of stroke subtypes and comorbidities}

Subtypes of stroke were divided into ischaemic stroke (ICD-9-CM 433-437) and haemorrhagic (ICD-9-CM 430-432), respectively. Brain image such as computed tomography $(\mathrm{CT})$ or magnetic resonance imaging (MRI) was used to verify the stroke diagnosis, which was not established if the patient was merely given stroke ICD codes without the procedure code of CT or MRI. Comorbidities known as major vascular risk factors including hypertension (ICD-9-CM 401-405), diabetes mellitus (ICD-9-CM 250), ischaemic heart diseases (ICD-9-CM 410-414), hyperlipidaemia (ICD9-CM 272) and atrial fibrillation (ICD-9-CM 427.3) were identified prior to the index date based on the above ICD classification.

\section{Statistical analyses}

Pearson chi-square test was administered to check the differences of categorical variables such as age groups, gender, hypertension, diabetes, ischaemic heart diseases, hyperlipidaemia and atrial fibrillation between the study and control cohort. After adjustment for the mentioned variables, Cox proportional hazard regressions were employed to evaluate the adjusted hazard ratio (HR) for the influence of PHDs on developing stroke. KaplanMeier analysis was performed to estimate the cumulative incidence of stroke for these two groups. Statistical Package for the Social Science version 22.0 (SPSS Inc., Chicago, IL, USA) was administered for all statistical analyses.

\section{Results}

In this study, we identified and included 1,346 patients diagnosed with PHDs and 5,384 age- and gendermatched controls for comparison. The demographic features were presented in Table 1, showing that the distribution of age, sex, and comorbidities of the study group were similar to the control group. The results revealed that 100 (incidence: 162.62/10,000 person-years) all stroke events developed in the study cohort and 287 (incidence: $116 / 10,000$ person-years) in the control group over a five-year observation period (Table 2). In the subgroup analysis, individuals with PHDs had a 1.49 times (95\% CI: $1.15-1.98, p<0.01$ ) higher risk to develop ischaemic stroke, instead of haemorrhagic stroke, compared with the control group (Table 2).

To investigate whether PHDs is an age-dependent risk factor for ischaemic stroke, we stratified patients into 3 groups by age $(<45,45$ to 64 , and $\geq 65$ years). The PHDs group had significantly greater risk for development of ischaemic stroke than the control cohort in the subgroup aged 45 to $64(\mathrm{HR}=1.50,95 \% \mathrm{CI}: 1.11-2.10$, 
Table 1 Baseline demographic status and co-morbidities compared between comparison and primary headache disorders (PHDs) group

\begin{tabular}{|c|c|c|c|}
\hline Variable & $\begin{array}{l}\text { PHDs cohort } \\
N=1,346 \\
(\%)\end{array}$ & $\begin{array}{l}\text { Comparison } \\
\text { cohort } \\
N=5,384 \text { (\%) }\end{array}$ & $p$-value \\
\hline$\overline{\text { Age, years }(S D)^{a}}$ & $47.38(14.56)$ & $46.74(15.77)$ & 0.183 \\
\hline$<45$ & $820(60.92)$ & $3,280(60.92)$ & \\
\hline $45-64$ & $404(30.01)$ & $1,616(30.01)$ & \\
\hline$\geq 65$ & $122(9.07)$ & $488(9.07)$ & \\
\hline Sex & & & 0.999 \\
\hline Female & $959(71.25)$ & $3,836(71.25)$ & \\
\hline Male & $387(28.75)$ & $1,548(28.75)$ & \\
\hline \multicolumn{4}{|l|}{ Co-morbidities } \\
\hline Hypertension & $72(5.35)$ & $305(5.66)$ & 0.342 \\
\hline DM & $25(1.86)$ & $101(1.88)$ & 0.732 \\
\hline $\mathrm{IHD}$ & $14(1.04)$ & $53(0.98)$ & 0.476 \\
\hline Hyperlipidaemia & $22(1.63)$ & $99(1.84)$ & 0.142 \\
\hline $\mathrm{AF}$ & $1(0.07)$ & $7(0.13)$ & 0.503 \\
\hline $\begin{array}{l}\text { Event (strokes) in the } \\
\text { endpoint }\end{array}$ & $100(7.43)$ & $287(5.33)$ & 0.002 \\
\hline Years of follow-up (SD) ${ }^{a}$ & $4.57(1.22)$ & $4.60(1.20)$ & 0.465 \\
\hline
\end{tabular}

Abbreviation: $S D$ standard deviation, $P H D$ s primary headache disorders, DM diabetes mellitus, IHD ischaemic heart disease, $A F$ atrial fibrillation astudent's $t$-test

$p<0.05)$. However, no significant difference was found between the PHDs group and matched controls with age $<45$ and $\geq 65$ years. We also examined if PHDs is a gender-dependent risk factor for developing ischaemic stroke using the Cox regression analysis. The result of gender-specific analysis revealed that women with PHDs had higher risk to develop ischaemic stroke $(\mathrm{HR}=1.49$, 95\% CI: $1.13-1.90, p<0.01)$ than those without PHDs.

Furthermore, we analyzed the incidence of stroke and stroke subtypes using multivariate Cox proportional hazards regression analysis according to time intervals. Our data revealed that patients with PHDs were likely to develop ischaemic stroke beyond 2 years after diagnosis $(\mathrm{HR}=1.40,95 \% \mathrm{CI}: 1.00-1.90, p<0.05)$ (Table 3). Significantly higher cumulative incidence of ischaemic stroke in the PHDs group than in the matched controls was observed by Kaplan-Meier analysis (Fig. 1).

We next investigated the impact of the PHDs subsets on stroke. Distribution of PHDs was presented in Additional file 1: Table S1. The subgroup analysis showed that patients with either migraine or tension-type headache had a higher risk to develop ischaemic stroke (Table 4). Compared to the nonPHDs group, the risks of ischaemic stroke were 1.22 (95\% CI: $1.13-1.97)$ and 2.29 (95\% CI: 1.22-2.80) times higher in migraine and tension-type headache group, respectively.

\section{Discussion}

In this nationwide, population-based cohort study, we found an incremental risk of ischaemic stroke in patients with PHDs. After adjusting for age, gender, and medical comorbidities, PHDs patients were more likely to develop ischemic stroke than matched controls. A subgroup analysis revealed that both migraine and tensiontype headache were associated with an increased risk of ischemic stroke. Moreover, we showed that female PHDs patients had higher likelihood to develop ischaemic stroke. In addition, we found that the middle age group (aged 45 to 64 years) with PHDs was more susceptible to development of ischaemic stroke. It is worth noting that the impact of PHDs on developing ischaemic stroke was significant with an interval of at least 2 years followup and increased over time.

Accumulating evidence has highlighted the association of ischaemic stroke with previous migraine [8, 14-16]. A meta-analysis reviewing 13 case-control, 10 cohort, and two cross sectional studies has suggested that migraine is one of independent risk factors for ischaemic stroke [14]. However, the power of this meta-analysis is restricted chiefly by the case-control nature of many of the researches, with their innate susceptibility to recall bias. Non-migraine or chronic headache has been linked to an incremental risk of all strokes $[17,18]$, but the evidence is conflicting. Neither of these studies compared the association of chronic headache with stroke subtypes. In this longitudinal study using nation-based database, we observed that patients with either migraine or tension-type headache had an increased risk for development of ischaemic stroke.

Recently, the mechanisms underlying migraine as a possible risk factor of ischaemic stroke have been postulated. Speculated mechanisms consist mainly of vasospasm [19, 20], prolonged of cortical spreading depression [21], platelet hyperaggregability [22, 23], increased prothrombotic factors [24, 25], endothelial abnormalities [26, 27] and alteration of arterial function [28]. In addition, a recent systemic review and meta-analysis study [29] has reported an association between migraine with myocardial infarction, The study suggests that the association is more obvious and evident in women, which was in line with results of the present study.

Recently, studies have shown a subcortical white matter (WM) hyperintensity in migraine patients [30, 31]. An incremental risk of WM hyperintensity has been observed in patients with tension-type headache, [32] indicating that the link spreads to non-migrainous headaches. WM hyperintensity has been suggested as an incomplete process of ischemia with a result of arteriolosclerosis of small vessels in the cerebrum [33]. It is also considered as small vessel alterations leading dysfunction of blood-brain barrier, and subsequent chronic 
Table 2 Incidence of stroke and stroke subtype and multivariate Cox proportional hazards regression analysis measured hazard ratio for study cohort

\begin{tabular}{|c|c|c|c|c|c|c|c|}
\hline \multirow[t]{2}{*}{ Variable } & \multicolumn{3}{|c|}{ PHDs cohort } & \multicolumn{3}{|c|}{ Comparison cohort } & \multirow{2}{*}{$\begin{array}{l}\text { Adjusted HR } \\
(95 \% \mathrm{Cl})\end{array}$} \\
\hline & Event & PYS & Rate & Event & PYs & Rate & \\
\hline All strokes & 100 & 6,149 & 162.62 & 287 & 24,742 & 116.00 & $1.40(1.13-1.68)^{* *}$ \\
\hline Haemorrhagic & 4 & 6,149 & 6.50 & 30 & 24,742 & 12.12 & $0.55(0.25-1.58)$ \\
\hline Ischaemic & 96 & 6,149 & 156.11 & 257 & 24,742 & 103.87 & $1.49(1.15-1.98)^{* *}$ \\
\hline \multicolumn{8}{|l|}{$<45$ years } \\
\hline All strokes & 13 & 2,951 & 44.05 & 33 & 12,539 & 26.32 & $1.66(0.79-2.97)$ \\
\hline Haemorrhagic & 1 & 2,951 & 3.39 & 7 & 12,539 & 5.58 & $0.63(0.10-4.00)$ \\
\hline Ischaemic & 12 & 2,951 & 40.66 & 26 & 12,539 & 20.73 & $1.95(0.97-3.74)$ \\
\hline \multicolumn{8}{|l|}{$45-64$ years } \\
\hline All strokes & 50 & 2,568 & 194.73 & 124 & 9,222 & 134.46 & $1.43(1.03-2.00)^{*}$ \\
\hline Haemorrhagic & 3 & 2,568 & 11.68 & 13 & 9,222 & 14.10 & $0.81(0.15-2.77)$ \\
\hline Ischaemic & 47 & 2,568 & 183.04 & 111 & 9,222 & 120.36 & $1.50(1.11-2.10)^{*}$ \\
\hline \multicolumn{8}{|l|}{$\geqq 65$ years } \\
\hline All strokes & 37 & 631 & 586.68 & 130 & 2,981 & 436.14 & $1.33(0.91-1.91)$ \\
\hline Haemorrhagic & 0 & 631 & 0 & 10 & 2,981 & 33.55 & 0 \\
\hline Ischaemic & 37 & 631 & 586.68 & 120 & 2,981 & 402.59 & $1.42(0.99-2.08)$ \\
\hline \multicolumn{8}{|l|}{ Male } \\
\hline All strokes & 35 & 1,730 & 202.36 & 101 & 6,918 & 146.00 & $1.37(0.91-2.02)$ \\
\hline Haemorrhagic & 3 & 1,730 & 17.35 & 15 & 6,918 & 21.68 & $0.80(0.25-2.70)$ \\
\hline Ischaemic & 32 & 1,730 & 185.02 & 86 & 6,918 & 124.32 & $1.46(0.91-2.10)$ \\
\hline \multicolumn{8}{|l|}{ Female } \\
\hline All strokes & 65 & 4,420 & 147.06 & 186 & 17,825 & 104.35 & $1.40(1.04-1.80)^{*}$ \\
\hline Haemorrhagic & 1 & 4,420 & 2.26 & 15 & 17,825 & 8.42 & $0.26(0.02-2.00)$ \\
\hline Ischaemic & 64 & 4,420 & 144.80 & 171 & 17,825 & 95.93 & $1.49(1.13-1.90)^{* *}$ \\
\hline
\end{tabular}

Model adjusted for age, sex, hypertension, DM, IHD, hyperlipidaemia, AF

Abbreviation: PYs person-years, Rate incidence rate, per 10,000 person-years, PHDs primary headache disorders, DM diabetes mellitus, IHD ischaemic heart disease, $A F$ atrial fibrillation; HR: hazard ratio

${ }^{*} p<0.05 ;{ }^{* *} p<0.01$

diffusion of macromolecules and fluids in the white matter; oxidative stress, dysfunction of endothelium and mechanisms involved in vascular regulation [34]. WM hyperintensity is related to an incremental risk for ischaemic stroke [35, 36]. As a result, subtle brain WM changes may lead to the higher risk for ischeamic stroke in PHDs patients. Further researches are necessary to verify these suppositions.

Compared to individuals without PHDs, patients with migraine had a null risk of haemorrhagic stroke in this study, which is consistent with the poor correlation between migraine and risk of haemorrhagic stroke in a previous study [37]. However, these findings differ from prior studies $[15,38]$ that indicated migraine was associated with an increased risk of haemorrhagic stroke. Moreover, migraine with aura rather than migraine without aura played a more important role in the overall increase of haemorrhagic stroke risk. Differences in methodological aspects and clinical settings might contribute to the discrepancies [39].

The prevalence of PHDs was higher for women than for men in our study as has been formerly reported [40]. This has been considered as a contribution of the effect of female hormones especially estrogen. Researches have shown that the risk for ischaemic stroke was increased in women who had migraine with aura and appeared to be exacerbated by smoking, oral contraceptive use and age $<45$ years [14]. Even though there are considerable methodological limitations in these studies [41]. Recent prospective cohort study [42] provided evidence that women with migraine were associated with an increased risk for major cardiovascular disease including myocardial infarction, stroke, and angina/coronary revascularization procedures, despite the mechanisms remain unclear. Similarly, the risk of ischaemic stroke was higher in the women with PHDs than in the control group in the present study. 
Table 3 Incidence of stroke and stroke subtype and multivariate Cox proportional hazards regression analysis measured hazard ratio for study cohort by various time intervals

\begin{tabular}{|c|c|c|c|c|c|c|c|}
\hline \multirow[t]{2}{*}{ Variable } & \multicolumn{3}{|c|}{ PHDs cohort } & \multicolumn{3}{|c|}{ Comparison cohort } & \multirow{2}{*}{$\begin{array}{l}\text { Adjusted HR } \\
(95 \% \mathrm{Cl})\end{array}$} \\
\hline & Event & PYS & Rate & Event & PYS & Rate & \\
\hline \multicolumn{8}{|l|}{ Follow $<1$ year } \\
\hline All strokes & 42 & 22 & $19,337.02$ & 96 & 57 & $16,949.15$ & $1.24(0.85-1.87)$ \\
\hline Haemorrhagic & 2 & 22 & 920.81 & 12 & 57 & $2,118.64$ & $0.49(0.14-2.10)$ \\
\hline Ischaemic & 40 & 22 & $18,416.21$ & 84 & 57 & $14,830.51$ & $1.31(0.91-1.88)$ \\
\hline \multicolumn{8}{|c|}{ Follow $\geqq 1,<2$ years } \\
\hline All strokes & 13 & 43 & $3,046.64$ & 55 & 176 & $3,122.52$ & $1.00(0.55-1.80)$ \\
\hline Haemorrhagic & 0 & 43 & 0 & 5 & 176 & 283.87 & 0 \\
\hline Ischaemic & 13 & 43 & $3,046.64$ & 50 & 176 & $2,838.65$ & $1.04(0.43-1.86)$ \\
\hline \multicolumn{8}{|l|}{ Follow $\geqq 2$ years } \\
\hline All strokes & 45 & 6,085 & 73.95 & 136 & 24,510 & 55.49 & $1.33(1.05-1.88)^{*}$ \\
\hline Haemorrhagic & 2 & 6,085 & 3.29 & 13 & 24,510 & 5.30 & $0.63(0.11-2.54)$ \\
\hline Ischaemic & 43 & 6,085 & 70.66 & 123 & 24,510 & 50.18 & $1.40(1.00-1.90)^{*}$ \\
\hline
\end{tabular}

Model adjusted for age, sex, hypertension, DM, IHD, hyperlipidaemia, AF

Abbreviation: PYs person-years, Rate incidence rate, per 10,000 person-years, PHDs primary headache disorders, DM diabetes mellitus, IHD ischaemic heart disease, $A F$ atrial fibrillation

${ }^{*} p<0.05$

Stroke is often considered an aging-related disorder, and the incidence of stroke grows with age among the general population. Researches show the risk of stroke approximately doubles each decade after age 55 [2]. However, strokes can develop at any age in reality. In this study, we found that the risk for development of ischaemic stroke was significantly greater in the PHDs group aged 45 to 64, instead of the elderly PHDs group (aged $\geq 65$ years), suggesting that increasing age was not an absolute risk factor for developing ischaemic stroke in individuals with PHDs. Our results that there was no significant

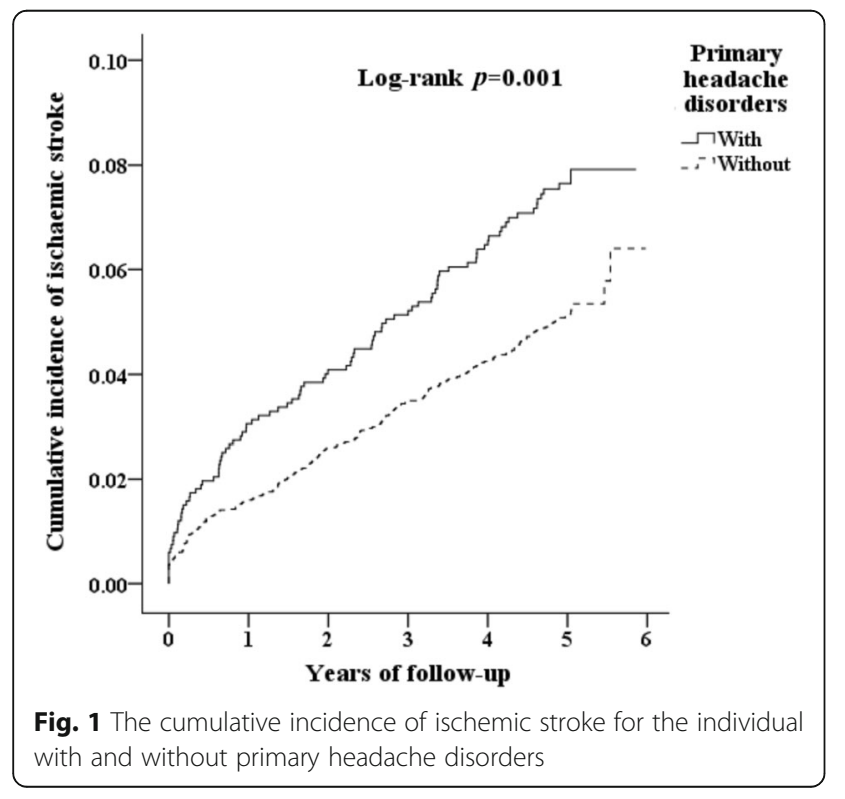

higher risk of ischaemic stroke in the PHDs group aged $<45$ years are in a disagreement with a previous study in which [14] migraine with aura was associated with an increased risk of ischemic stroke and the increase appeared to be exacerbated by smoking, oral contraceptive use and age $<45$ years. The differences might be explained by study designs and environmental factors involved. Furthermore, the impact of PHDs on ischaemic stroke risk was significant after 2 years of follow-up and increased over time, supporting the hypothesis of the chronic effect of PHDs on ischaemic stroke risk.

\section{Study limitations}

There are certain limitations in this study. Firstly, medication likes hormonal contraceptives or life habits, such as smoking, drinking, customs of exercise and food that may affect the stroke risk did not include in the study. Secondly, our data from the huge database may comprise unrecognized recurrent individuals that may have suffered PHDs and stroke prior to1996 when NIH began to administer. Moreover, coding error might happen in the dataset. Thirdly, potential diagnosis biases and misclassification might exist due to the diagnoses of PHDs were ascertained retrospectively without further confirmations by headache experts. At last, our results only revealed an association instead of demonstrating straightforward relationship. Further researches are necessary to elaborate the mechanism underlying the association showed in this study. 
Table 4 Incidence of stroke and stroke subtype and multivariate Cox proportional hazards regression analysis measured hazard ratio for study cohort by PHDs subtype

\begin{tabular}{|c|c|c|c|c|c|c|c|}
\hline \multirow[t]{2}{*}{ Variable } & \multicolumn{3}{|c|}{ PHDs cohort } & \multicolumn{3}{|c|}{ Comparison cohort } & \multirow{2}{*}{$\begin{array}{l}\text { Adjusted HR } \\
(95 \% \mathrm{Cl})\end{array}$} \\
\hline & Event & PYs & Rate & Event & PYs & Rate & \\
\hline \multicolumn{8}{|l|}{ Total } \\
\hline All strokes & 100 & 6,149 & 162.62 & 287 & 24,742 & 116.00 & $1.40(1.13-1.68)^{* *}$ \\
\hline Haemorrhagic & 4 & 6,149 & 6.50 & 30 & 24,742 & 12.12 & $0.55(0.25-1.58)$ \\
\hline Ischaemic & 96 & 6,149 & 156.11 & 257 & 24,742 & 103.87 & $1.49(1.15-1.98)^{* *}$ \\
\hline \multicolumn{8}{|l|}{ Migraine } \\
\hline All strokes & 65 & 5,235 & 124.16 & 287 & 24,742 & 116.00 & $1.15(1.04-1.69)^{*}$ \\
\hline Haemorrhagic & 3 & 5,235 & 5.73 & 30 & 24,742 & 12.12 & $0.44(0.21-1.57)$ \\
\hline Ischaemic & 62 & 5,235 & 118.43 & 257 & 24,742 & 103.87 & $1.22(1.13-1.97)^{*}$ \\
\hline \multicolumn{8}{|c|}{ Tension-type headache } \\
\hline All strokes & 35 & 996 & 351.41 & 287 & 24,742 & 116.00 & $2.16(1.25-2.77)^{* *}$ \\
\hline Haemorrhagic & 1 & 996 & 10.04 & 30 & 24,742 & 12.12 & $0.86(0.23-1.64)$ \\
\hline Ischaemic & 34 & 996 & 341.37 & 257 & 24,742 & 103.87 & $2.29(1.22-2.80)^{* *}$ \\
\hline
\end{tabular}

Model adjusted for age, sex, hypertension, DM, IHD, hyperlipidaemia, AF

Abbreviation: PYs person-years, Rate incidence rate, per 10,000 person-years, PHDs primary headache disorders, DM diabetes mellitus, IHD ischaemic heart disease, $A F$ atrial fibrillation

${ }^{*} p<0.05 ;{ }^{* *} p<0.01$

\section{Conclusion}

In this study, we provide subjective evidence supporting the hypothesis that PHDs patients are at relatively high risk for developing ischaemic stroke. The increase in the risk of ischaemic stroke associated with PHDs was mainly associated with migraine and tension-type headache rather than other primary headaches. PHDs are considered to be an age-specific, gender dependent and time-dependent risk factor of ischaemic stroke. These findings suggest that preventive strategies of ischaemic stroke might be ameliorated by being more careful with subgroups of patients, especially middleaged (45- to 64-year) and female individuals with PHDs.

\section{Additional file}

Additional file 1: Table S1. Distribution of PHDs. (DOC 55 kb)

\section{Acknowledgements}

This study is based in part on data from the National Health Insurance Research Database provided by the Bureau of National Health Insurance, Department of Health and managed by National Health Research Institutes. The interpretation and conclusions contained herein do not represent those of National Health Insurance Administration, Department of Health or National Health Research Institutes.

\section{Funding}

This study was supported in part by grants from the Tri-Service General Hospital (TSGH-C104-084; TSGH-C105-084; TSGH-C100-101; TSGH-C101-080; TSGH-C103-085; TSGH-C104-083; TSGH-C105-085), Ministry of Science and Technology (MOST104-2314-B-016-017-MY3; MOST 105-2314-B-016-004-), Teh-Tzer Study Group for Human Medical Research Foundation (A1031031).
The funders had no role in study design, data collection and analysis, decision to publish, or preparation of the manuscript.

\section{Disclosure statement}

This was not an industry supported study. The authors have indicated no financial conflicts of interest.

\section{Authors' contributions}

CLT carried out clinical studies, experimental studies, data acquisition, statistical analysis, drafting of the manuscript, manuscript editing and manuscript review. CHC, PJL, JHY, SYC, CCL, YFS, FCY, CHC, WCC, CKT participated in study concepts, experimental studies, data acquisition, statistical analysis, manuscript review. JTL was the guarantor of integrity of the entire study, and conceived of study concepts, study design, participated in experimental studies, data acquisition, statistical analysis, drafting of the manuscript, manuscript review, obtaining funding. All authors read and approved the final manuscript.

\section{Competing interests}

This was not an industry supported study. The authors declare that they have no competing interests.

\section{Author details}

${ }^{1}$ Department of Neurology, Tri-Service General Hospital, National Defense Medical Center, No.325, Sec. 2, Cheng-Kung Road, 11490 Taipei, Taiwan, Republic of China. ${ }^{2}$ Graduate Institute of Medical Sciences, National Defense Medical Center, Taipei, Taiwan, ROC. ${ }^{3}$ Departments of Nursing, Tri-Service General Hospital, National Defense Medical Center, Taipei, Taiwan, ROC. ${ }^{4}$ Division of Neurology, Department of Medicine, Cheng Hsin General Hospital, Taipei, Taiwan, ROC. ${ }^{5}$ Department of Neurology, Cardinal Tien Hospital, New Taipei City, Taiwan, ROC. ${ }^{6}$ Department of Hyperbaric Medicine, Cardinal Tien Hospital, New Taipei City, Taiwan, ROC. 7 School of Medicine, Fu-Jen Catholic University, New Taipei City, Taiwan, ROC. ${ }^{8}$ Taiwanese Injury Prevention and Safety Promotion Association, Taipei, Taiwan, ROC. ${ }^{9} \mathrm{School}$ of Public Health, National Defense Medical Center, Taipei, Taiwan, ROC.

${ }^{10}$ Department of Medical Research, Tri-Service General Hospital, National Defense Medical Center, Taipei, Taiwan, ROC. 


\section{References}

1. Murray CJ, Lopez AD (1997) Mortality by cause for eight regions of the world: Global Burden of Disease Study. Lancet 349:1269-1276

2. Fonarow GC, Reeves MJ, Zhao X et al (2010) Age-related differences in characteristics, performance measures, treatment trends, and outcomes in patients with ischaemic stroke. Circulation 121:879-891

3. Whisnant JP (1997) Modeling of risk factors for ischaemic stroke. The Willis Lecture. Stroke 28:1840-1844

4. Donnan GA, Fisher M, Macleod M, Davis SM (2008) Stroke. Lancet 371:1612-1623

5. Headache Classification Committee of the International Headache Society (IHS) (2013) The International Classification of Headache Disorders, 3rd edition (beta version). Cephalalgia 33:629-808

6. Lantéri-Minet M, Duru G, Mudge M, Cottrell S (2011) Quality of life impairment, disability and economic burden associated with chronic daily headache, focusing on chronic migraine with or without medication overuse: a systematic review. Cephalalgia 14:837-850

7. Abu Bakar N, Tanprawate S, Lambru G, Torkamani M, Jahanshahi M, Matharu M (2016) Quality of life in primary headache disorders: A review. Cephalalgia 36:67-91

8. Spector JT, Kahn SR, Jones MR, Jayakumar M, Dalal D, Nazarian S (2010) Migraine headache and ischaemic stroke risk: an updated meta-analysis. Am J Med 123:612-624

9. World Health Organization: Headache disorders. Fact sheet. Available from URL: http://www.who.int/mediacentre/factsheets/fs277/en/. Accessed on 22 Apr 2016

10. Steiner TJ (2005) Lifting the burden: the global campaign to reduce the burden of headache worldwide. J Headache Pain 6:373-377

11. National Health Insurance Research Database, Taiwan. Available from URL: http://nhird.nhri.org.tw/en/index.html. Accessed 31 Oct 2016

12. Kang JH, Chen YH, Lin HC (2010) Comorbidity profiles among patients with ankylosing spondylitis: a nationwide population-based study. Ann Rheum Dis 69:1165-1168

13. Shen CC, Tsai SJ, Perng CL, Kuo Bl, Yang AC (2013) Risk of Parkinson disease after depression: a nationwide population-based study. Neurology 81:1538-1544

14. Schurks M, Rist PM, Bigal ME, Buring JE, Lipton RB, Kurth T (2009) Migraine and cardiovascular disease: systematic review and meta-analysis. BMJ 339: b3914

15. Kurth T, Kase CS, Schürks M, Tzourio C, Buring JE (2010) Migraine and risk of haemorrhagic stroke in women: prospective cohort study. BMJ 341:c3659

16. Monteith TS, Gardener H, Rundek T, Elkind MSV, Sacco RL (2015) Migraine and risk of stroke in older adults: Northern Manhattan Study. Neurology 85: 715-721

17. Jousilahti P, Tuomilehto J, Rastenyte D, Vartiainen E (2003) Headache and the risk of stroke: a prospective observational cohort study among 35,056 Finnish men and women. Arch Intern Med 163:1058-1062

18. Merikangas KR, Fenton BT, Cheng SH, Stolar MJ, Risch N (1997) Association between migraine and stroke in a large-scale epidemiological study of the United States. Arch Neurol 54:362-368

19. Woods RP, lacoboni M, Mazziotta JC (1994) Brief report: bilateral spreading cerebral hypoperfusion during spontaneous migraine headache. N Engl J Med 331:1689-1692

20. Olesen J, Friberg L, Olsen TS et al (1993) Ischaemia-induced (symptomatic) migraine attacks may be more frequent than migraine-induced ischaemic insults. Brain 116(Pt 1):187-202

21. Kurth T, Chabriat H, Bousser MG (2012) Migraine and stroke: a complex association with clinical implications. Lancet Neurol 11:92-100

22. D'Andrea G, Hasselmark L, Alecci M et al (1994) Platelet secretion from dense and alpha-granules in vitro in migraine with or without aura. J Neurol Neurosurg Psychiatry 57:557-561

23. Zeller JA, Frahm K, Baron R et al (2004) Platelet-leukocyte interaction and platelet activation in migraine: a link to ischaemic stroke? J Neurol Neurosurg Psychiatry 75:984-987

24. Hering-Hanit R, Friedman Z, Schlesinger I, Ellis M (2001) Evidence for activation of the coagulation system in migraine with aura. Cephalalgia 21:137-139

25. Waeber C, Moskowitz MA (2005) Migraine as an inflammatory disorder. Neurology 64:S9-S15

26. Mawet J, Kurth T, Ayata C (2015) Migraine and stroke: in search of shared mechanisms. Cephalalgia 35:165-181

27. Tietjen GE (2009) Migraine as a systemic vasculopathy. Cephalalgia 29:987-996
28. Sacco S, Ripa P, Grassi D et al (2013) Peripheral vascular dysfunction in migraine: a review. J Headache Pain 14:80

29. Sacco S, Ornello R, Ripa P et al (2015) Migraine and risk of ischaemic heart disease: a systematic review and meta-analysis of observational studies. Eur J Neurol 22:1001-1011

30. Vermeer SE, Prins ND, den Heijer T, Hofman A, Koudstaal PJ, Breteler MM (2003) Silent brain infarcts and the risk of dementia and cognitive decline. N Engl J Med 348:1215-1222

31. Kruit MC, van Buchem MA, Launer LJ, Terwindt GM, Ferrari MD (2010) Migraine is associated with an increased risk of deep white matter lesions, subclinical posterior circulation infarcts and brain iron accumulation: the population-based MRI CAMERA study. Cephalalgia 30:129-136

32. Bell BD, Primeau M, Sweet JJ, Lofland KR (1999) Neuropsychological functioning in migraine headache, nonheadache chronic pain, and mild traumatic brain injury patients. Arch Clin Neuropsychol 14:389-399

33. Tana C, Tafuri E, Tana M et al (2013) New insights into the cardiovascular risk of migraine and the role of white matter hyperintensities: is gold all that glitters? J Headache Pain 14:9

34. Xiong YY, Mok V (2011) Age-related white matter changes. J Aging Res 2011:617927

35. Kuller LH, Longstreth WT Jr, Arnold AM et al (2004) White matter hyperintensity on cranial magnetic resonance imaging: a predictor of stroke. Stroke 35:1821-1825

36. Debette S, Markus HS (2010) The clinical importance of white matter hyperintensities on brain magnetic resonance imaging: systematic review and meta-analysis. BMJ 341:c3666

37. Gaist D, González-Pérez A, Ashina M, Rodríguez LA (2014) Migraine and risk of hemorrhagic stroke: a study based on data from general practice. Headache Pain 15:74

38. Sacco S, Ornello R, Ripa P, Pistoia F, Carolei A (2013) Migraine and hemorrhagic stroke: a meta-analysis. Stroke 44:3032-3038

39. Ornello R, Pistoia F, Degan D, Carolei A, Sacco S (2015) Migraine and hemorrhagic stroke: data from general practice. J Headache Pain 16:8

40. Macgregor EA, Rosenberg JD, Kurth T (2011) Sex-related differences in epidemiological and clinic-based headache studies. Headache 51:843-859

41. Petitti DB (2003) Clinical practice. Combination estrogen-progestin oral contraceptives. N Engl J Med 349:1443

42. Kurth T, Winter AC, Eliassen AH et al (2016) Migraine and risk of cardiovascular disease in women: prospective cohort study. BMJ 353:i2610

\section{Submit your manuscript to a SpringerOpen ${ }^{\circ}$ journal and benefit from:}

- Convenient online submission

- Rigorous peer review

- Immediate publication on acceptance

- Open access: articles freely available online

- High visibility within the field

- Retaining the copyright to your article

Submit your next manuscript at $>$ springeropen.com 